1976 june • volume 50 • no. 2 •pages 59-142

\title{
Jouimal of Helminthology
}

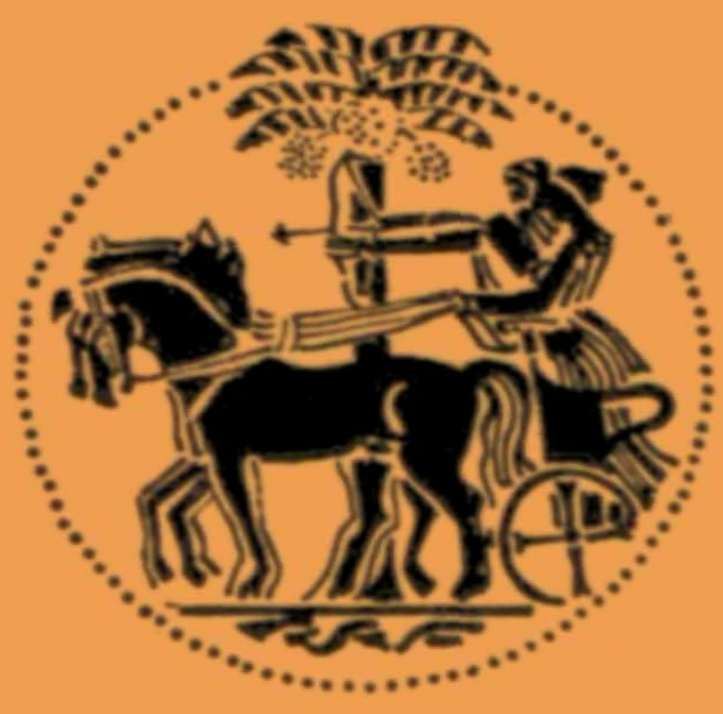

London School of of Hygiene and Tropical Medicine 


\section{JOURNAL OF HELMINTHOLOGY}

(Founded by R. T. Leiper in 1923 and edited from 1946-72 by J. J. C. Buckley)

EDITOR: Dr. R. L. Muller,

Department of Medical Helminthology,

London School of Hygiene \& Tropical Medicine,

Keppel Street, London WC1E 7HT, England.

Subscriptions and enquiries may be sent to:

Bureau of Hygiene \& Tropical Diseases,

Keppel Street,

London WCIE 7HT, England.

Published in 4 parts per year

Subscription $£ 9.00$ per annum 